chr13: | $31,740,000|31,745,000| 31,750,000|31,755,000| 31,760,000|31,765,000| 31,770,000|31,775,000| 31,780,000|31,785,000| 31,790,000|31,795,000| 31,800,000|31,805,000|$

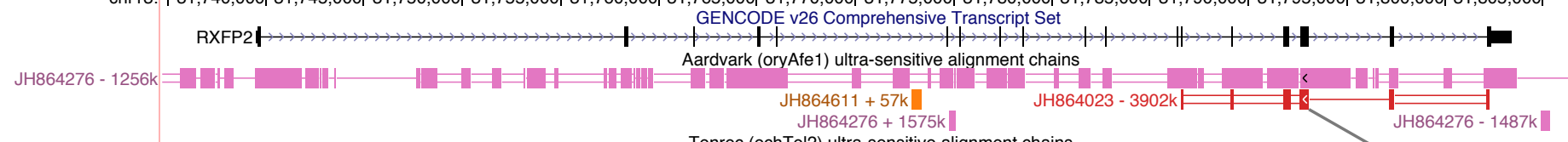
JH980395 - 3864k Cape golden mole (chrAsi1) ultra-sensitive alignment chains JH980395-3864k Cape golden mole (chrAsi1) ultra-sensitive alignment chains

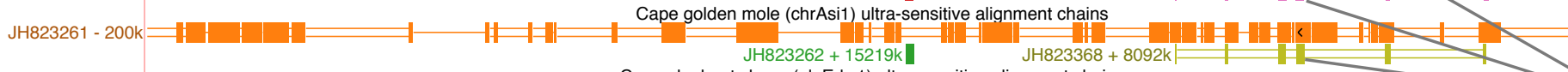
$\mathrm{JH} 947133+34764 \mathrm{k}=\quad$ Cape elephant shrew (eleEdw1) ultra-sensitive alignment chains

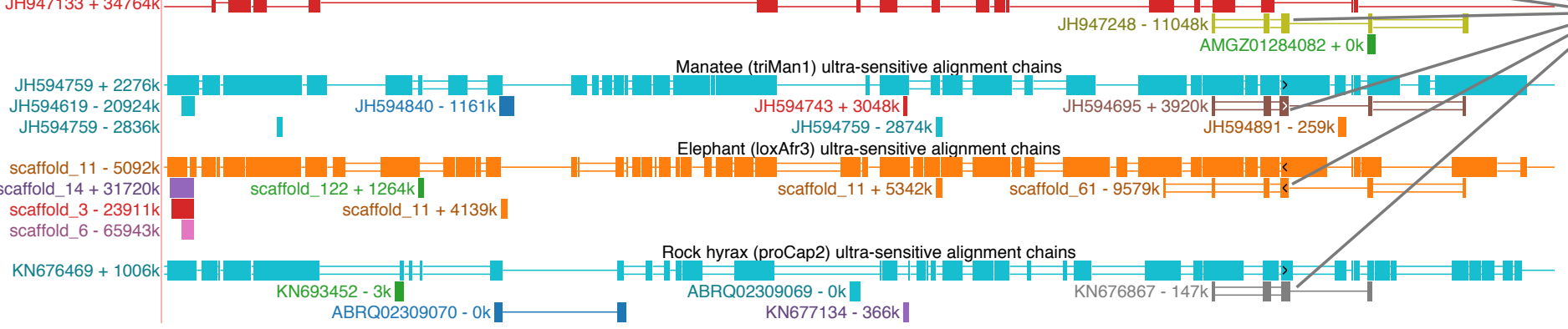
JH594840-1161k JH594743 + 3048k JH594759 - 2874k scaffold $122+1264 \mathrm{k}$ $\mathrm{JH} 594695+3920 \mathrm{k}$ JH594891-259k scaffold_11+4139k Rock hyrax (proCap2) ultra-sensitive alignment chains ABRQ02309069-0k KN677134 - 366k

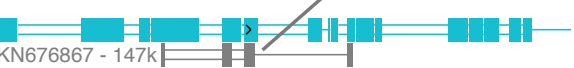
更

\title{
B INSL3
}

Scale

$2 \mathrm{~kb}$ hg38

chr19:

$17,816,500 \mid \quad 17,817,000$

$2 \mathrm{~kb}$

GENCODE v26 Comprehensive Transcript Set

$\mathrm{JH} 863854+83 \mathrm{k}$ - $1|-||||||||\gg\rangle)>=$

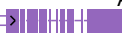

Aardvark (oryAfe1) ultra-sensitive alignment chains Tenrec (echTel2) ultra-sensitive alignment chains

$\mathrm{JH} 823630+0 \mathrm{~K}$

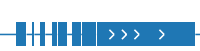

Cape golden mole (chrAsi1) ultra-sensitive alignment chains

> - >

JH947355 - 32k

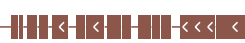

Cape

elephant shrew (eleEdw1) ultra-sensitive alignment chains

JH594728 - 5148k

scaffold_26 - 24013k

$|H<<-1-1|<<<<$

$<H<<\mid+$ Man

Manatee (triMan1) ultra-sensitive alignment chains

Eleph

$<<<1$

KN680258-304k

$-1<|-|-1 \mid<\ll<$

Rock hyrax (proCap2) ultra-sensitive alignment chains

$<<<$ 